\title{
The Role of Protein Synthesis in Striatal Long-Term Depression
}

\author{
Henry H. Yin, Margaret I. Davis, Jennifer A. Ronesi, and David M. Lovinger \\ Section on Synaptic Pharmacology, Laboratory for Integrative Neuroscience, National Institute on Alcohol Abuse and Alcoholism, National Institutes of \\ Health, Bethesda, Maryland 20892
}

\begin{abstract}
Long-term depression (LTD) at the corticostriatal synapse is postsynaptically induced but presynaptically expressed, the depression being a result of retrograde endocannabinoid signaling that activates presynaptic cannabinoid $\mathrm{CB}_{1}$ receptors and reduces the probability of glutamate release. To study the role of protein synthesis in striatal LTD, we used a striatum-only preparation in which the presynaptic cell body is cut off, leaving intact only its axons, whose terminals synapse on medium spiny neurons. LTD (duration $>150$ min) was induced in this preparation, thus providing evidence that transcription in the presynaptic cell nucleus is not necessary for this form of plasticity. The maintenance of striatal LTD, however, was blocked by bath application of protein translation inhibitors but not by the same inhibitors loaded into the postsynaptic cell. These results suggest that local translation is critical for the expression of striatal LTD, distinguishing this form of mammalian synaptic plasticity from other forms that require postsynaptic protein synthesis. Possible roles of axonal or glial translation in striatal LTD are considered.
\end{abstract}

Key words: long-term depression; protein synthesis; cycloheximide; translation; striatum; endocannabinoid; plasticity

\section{Introduction}

The striatum, the major input nucleus of the basal ganglia, plays critical roles in the control of voluntary behavior and habit formation (Cromwell and Berridge, 1996; Jog et al., 1999; Yin et al., 2004, 2006). The dorsolateral (DLS) or sensorimotor striatum in the rat, similar to the putamen in primates, receives inputs from primary sensorimotor cortices and sends projections that, coursing through the intrinsic basal ganglia circuitry, ultimately influence motor control networks in the brainstem as well as the ventral thalamus (Nauta, 1989; Joel and Weiner, 2000).

Plasticity of cortical synaptic inputs to DLS is thought to play a role in striatum-dependent learning and memory (Graybiel, 1998; Gerdeman et al., 2003). The best understood form of longterm plasticity in this region is long-term depression (LTD) at the corticostriatal synapse induced by tetanic high-frequency stimulation (HFS) combined with postsynaptic depolarization (Calabresi et al., 1992a; Lovinger et al., 1993). Striatal LTD is induced postsynaptically in the medium spiny neuron (MSN), the projection neuron of the striatum, and expressed presynaptically, most likely in the form of reduced glutamate release from the terminals of pyramidal neurons in the cortex (Choi and Lovinger, 1997). The reduction in presynaptic glutamate release requires synthesis of, and retrograde signaling by, endocannabinoids from the postsynaptic neuron and the subsequent activation of cannabinoid $\mathrm{CB}_{1}$ receptors at the presynaptic terminal (Gerdeman et al.,

Received July 26, 2006; revised 0ct. 3, 2006; accepted 0ct. 4, 2006

This research was supported by the Division of Intramural Clinical and Basic Research of the National Institute on Alcohol Abuse and Alcoholism-National Institutes of Health.

Correspondence should be addressed to David M. Lovinger, National Institute on Alcohol Abuse and AlcoholismNational Institutes of Health, 5625 Fishers Lane, TS-13, Bethesda, MD 20892. E-mail: lovindav@willco.niaaa.nih.gov. DOI:10.1523/JNEUROSCI.3196-06.2006

Copyright $\odot 2006$ Society for Neuroscience $\quad$ 0270-6474/06/2611811-10\$15.00/0
2002). Although $\mathrm{CB}_{1}$ receptor activation is necessary for the induction of LTD, it is not necessary for its maintenance (Gerdeman et al., 2002, 2003; Ronesi et al., 2004).

To elucidate the mechanisms underlying the maintenance of LTD in the DLS, we examined the role of protein synthesis in this form of plasticity. The clear separation of presynaptic and postsynaptic neurons by the corpus callosum and the presynaptic site of expression for striatal LTD permit the use of a novel striatum-only preparation, in which the cortical cell bodies are removed, leaving only their axons that synapse on striatal neurons. This preparation thus eliminates the possibility of transcription in the presynaptic cell nucleus in response to LTDinducing stimulation.

We first demonstrated long-lasting LTD in the striatum-only preparation. Although this form of LTD does not require presynaptic transcription, it was blocked by bath application of translation inhibitors. Using whole-cell patch-clamp recording, we showed that neither transcription nor translation in the postsynaptic neuron is required for striatal LTD. Having ruled out these possibilities, we discuss other possible sites for translation, in particular the presynaptic terminal itself.

\section{Materials and Methods}

Brain slice preparation. Brain slices containing both striatum and cortex, from postnatal day 15 (P15) to P25 Sprague Dawley rats, were prepared as described previously (Gerdeman et al., 2002). The rats were deeply anesthetized with halothane before decapitation; their brains were transferred rapidly to ice-cold modified artificial CSF (aCSF) containing the following (in mM): 194 sucrose, $30 \mathrm{NaCl}, 4.5 \mathrm{KCl}, 1 \mathrm{MgCl}_{2}, 26 \mathrm{NaHCO}_{3}$, $1.2 \mathrm{NaH}_{2} \mathrm{PO}_{4}$, and $10 \mathrm{D}$-glucose. Modified aCSF was brought to $\mathrm{pH} 7.4$ by aeration with $95 \% \mathrm{O}_{2} / 5 \% \mathrm{CO}_{2}$. Coronal sections (350-400 $\mu \mathrm{m}$ thick) were cut in ice-cold modified aCSF using a Vibrotome 1000 (Warner Instruments, Hamden, CT). Slices were transferred immediately to a 
nylon net submerged in normal aCSF containing the following (in $\mathrm{mM}$ ): $124 \mathrm{NaCl}, 4.5 \mathrm{KCl}, 2 \mathrm{CaCl}_{2}, 1 \mathrm{MgCl}_{2}, 26 \mathrm{NaHCO}_{3}, 1.2 \mathrm{NaH}_{2} \mathrm{PO}_{4}$, and 10 D-glucose. Normal aCSF was maintained at $\mathrm{pH} 7.4$ by bubbling with $95 \%$ $\mathrm{O}_{2} / 5 \% \mathrm{CO}_{2}$ at room temperature $\left(21-24^{\circ} \mathrm{C}\right)$. The cortex was then cut from the striatum using a pair of iridectomy scissors and removed from the incubation chamber. After at least $1 \mathrm{~h}$ of incubation at room temperature, hemi-slices were transferred to a recording chamber, submerged in normal aCSF (osmolarity adjusted to $315 \mathrm{mOsm}$ ) containing $50 \mu \mathrm{m}$ picrotoxin (to prevent contamination of EPSCs by $\mathrm{GABA}_{\mathrm{A}}$ receptormediated responses), and maintained at $29-31^{\circ} \mathrm{C}$ stable within $1^{\circ} \mathrm{C}$ during any given experiment.

The preparation of slices for the (RS)-3,5-dihydroxyphenylglycine (DHPG) experiments (striatum and hippocampus) and experiments examining metabotropic glutamate receptor (mGluR)-mediated EPSCs was similar to that described above with three exceptions. First, slightly older rats were used (P21-P25) for the hippocampal LTD and mGluR EPSC experiments. Previous work has established that, for DHPGinduced LTD at the CA1 synapse, the requirement for postsynaptic protein synthesis only emerges after approximately P21 (Nosyreva and Huber, 2005). Second, before slice preparation, the rats were deeply anesthetized with halothane and transcardially perfused with ice-cold modified aCSF before decapitation. Approximately $15 \mathrm{ml}$ of modified aCSF was quickly perfused into the left ventricle with a $25 \mathrm{ml}$ syringe, while the right atrium is cut open. Transcardial perfusion improves the health of the slices, especially in older animals, as judged by the increase in healthy neuronal profiles observed with differential interference contrast (DIC) imaging. This procedure was used for experiments examining the effects of cycloheximide on baseline synaptic transmission (see Fig. 3) and on mGluR-mediated currents (see Fig. 6), as well as in experiments examining DHPG effects on transmission. Finally, to prevent any increase in excitability of CA3 neurons caused by DHPG treatment in hippocampal slices, the CA3 region of the hippocampus was removed with a pair of iridectomy scissors after slicing.

Field potential recording. Extracellular field recordings were obtained with micropipettes (2.5-5 M 2 ) filled with $1 \mathrm{M} \mathrm{NaCl}$ solution. Stimulus intensity was set to yield an evoked population spike (PS) amplitude approximately half the size of the maximal evoked response. The halfmaximal responses were $0.4-1.5 \mathrm{mV}$ and were evoked with stimuli $0.3-$ $0.8 \mathrm{~mA}$ in intensity and $0.01-0.05 \mathrm{~ms}$ in duration. The HFS protocol used to induce LTD in field potential recordings consisted of four $1 \mathrm{~s}, 100 \mathrm{~Hz}$ trains delivered every $10 \mathrm{~s}$.

Whole-cell voltage-clamp recording. Whole-cell recordings from MSNs were performed as described previously (Gerdeman et al., 2002). Pipettes were pulled from borosilicate glass capillaries on a Flaming-Brown (Novato, CA) micropipette puller. Test stimuli were delivered via a Master-8 stimulator (A.M.P.I., Jerusalem, Israel) at a frequency of $0.05 \mathrm{~Hz}$ through a bipolar twisted tungsten wire placed in the DLS. Pipette resistance ranged from 2.5 to $5 \mathrm{M} \Omega$ when filled with an internal solution containing the following (in mM): 120 cesium methane sulfonate, $5 \mathrm{NaCl}, 10$ tetraethylammonium chloride, 10 HEPES, 4 lidocaine $N$-ethyl bromide, 1.1 EGTA, $4 \mathrm{Mg}$-ATP, and $0.3 \mathrm{Na}-\mathrm{GTP}$, pH adjusted to 7.2 with $\mathrm{CsOH}$ (osmolarity set to $298 \mathrm{mOsm}$ with sucrose). Recordings were made from medium spiny neurons (soma diameter of $10-20 \mu \mathrm{m}$ ) identified visually with the aid of DIC-enhanced visual guidance from neurons two or more layers (soma diameter) below the slice surface. Cells were voltage clamped at $-70 \mathrm{mV}$ throughout the experiments (except during pairing with high-frequency stimulation or during the striatal DHPG experiment, in which cells were clamped at $-50 \mathrm{mV}$ to allow the activation of L-type calcium channels), and the stimulus intensity was set to the level at which EPSC amplitude was 200-400 pA. We analyzed only recordings with series resistance $<30 \mathrm{M} \Omega$. The series resistance, usually ranging from 8 to $20 \mathrm{M} \Omega$, was not compensated, and, if it changed by $>20 \%$ during the course of an experiment, the cell was discarded.

For experiments examining the effect of cycloheximide on mGluRmediated synaptic current, $50 \mu \mathrm{M}$ picrotoxin, $50 \mu \mathrm{M} \mathrm{APV}$, and $20 \mu \mathrm{M}$ 2,3-dihydroxy-6-nitro-7-sulfonyl-benzo[f] quinoxaline (NBQX) were present in the bath solution to isolate mGluR-mediated slow current. Only rats ranging from 19 to $25 \mathrm{~d}$ of age were used for these experiments. A single train of 10 pulses at $100 \mathrm{~Hz}$ was used to obtain mGluR-mediated slow current; $100 \quad \mu \mathrm{M}$ CPCCOEt [7-(hydroxyimino)cyclopropa chromen-1a-carboxylate ethyl ester] (mGluR 1 antagonist) and $20 \mu \mathrm{M}$ 2-methyl-6-(phenylethynyl)-pyridine (MPEP) (mGluR 5 antagonist) were used to confirm that the current recorded was indeed mediated by group I mGluRs.

Synaptic currents were recorded with an Axopatch 1D amplifier (Molecular Devices, Palo Alto, CA), filtered at $5 \mathrm{kHz}$, digitized at $10 \mathrm{kHz}$, and stored on a Dell microcomputer (Dell Computer Company, Round Rock, TX). EPSC amplitudes were examined using peak detection software in pClamp8 (Molecular Devices). The HFS protocol used to induce LTD was paired with depolarization of the postsynaptic cell to $0 \mathrm{mV}$ and consisted of four $1 \mathrm{~s}, 100 \mathrm{~Hz}$ trains delivered every $10 \mathrm{~s}$. Paired pulse ratio (PPR) was determined by calculating the ratio of the amplitude of the second EPSC peak to that of the first EPSC ( $50 \mathrm{~ms}$ interstimulus interval). To determine whether there was LTD, the amplitude of the responses during the $10 \mathrm{~min}$ before HFS was averaged and compared with the amplitude of the responses 20-30 min after HFS. For the DHPG experiment, responses during the $10 \mathrm{~min}$ before DHPG application were compared with responses 20-30 min after the beginning of DHPG application. Picrotoxin at $50 \mu \mathrm{M}$ and APV at $50 \mu \mathrm{m}$ were present in the external solution in all experiments, except the striatal DHPG experiment, in which APV was not present in the solution, following the protocol used by Kreitzer and Malenka (2005). Unless indicated otherwise, statistical significance was assessed with paired $t$ tests for within-subject planned comparisons and unpaired $t$ tests for between-subject planned comparisons.

Western blotting. Coronal brain slices (350 $\mu \mathrm{m}$ thick) were cut as described above from two rats (P16 and P18). Slices were incubated in aCSF at room temperature for $1 \mathrm{~h}$, were then divided into three treatment groups, and were transferred to a custom-made six-well incubation chamber. The control group was incubated in aCSF as before. After 30 $\mathrm{min}$, the phorbol-12-myristate-13-acetate (PMA) group was treated with $1 \mu \mathrm{M}$ PMA for $30 \mathrm{~min}$; the cycloheximide plus PMA group was pretreated with $80 \mu \mathrm{M}$ cycloheximide for $30 \mathrm{~min}$, followed by $1 \mu \mathrm{M}$ PMA for another $30 \mathrm{~min}$. The slices were then immediately removed from the incubation chamber and frozen on dry ice for $10 \mathrm{~min}$. Controls received media changes appropriate for experimental groups. Slices were sonicated in lysis buffer [ $1 \%$ Triton X-100 containing protease inhibitors (Sigma, St. Louis, $\mathrm{MO}$ ) and $10 \mathrm{~mm}$ Tris, $\mathrm{pH}$ 6.8], and protein levels were determined using the BCA assay (Pierce, Rockford, IL). Samples were diluted with $2 \times$ sample buffer $(0.5 \mathrm{mg} / \mathrm{ml}$ bromophenol blue, $2.5 \%$ SDS, $25 \%$ glycerol, 6\% 2-mercaptoethanol, and $100 \mathrm{~mm}$ Tris, $\mathrm{pH}$ 6.8) and boiled for 5 min. Protein $(20 \mu \mathrm{g})$ was fractionated on $10 \%$ SDS-polyacrylamide gels and transferred to polyvinylidene difluoride membranes for immunodetection. The membranes were blocked for $1 \mathrm{~h}$ with $5 \%$ nonfat powdered milk in $25 \mathrm{~mm}$ Tris-buffered saline and $0.05 \%$ Tween 20 (TTBS) and probed overnight with anti-c-Fos 1:1000 in TTBS (Upstate Biotechnology, Lake Placid, NY). The next day, they were washed three times for 10 min in TTBS, followed by $1 \mathrm{~h}$ incubation with horseradish peroxidaseconjugated anti-rabbit antibody (1:1000 in TTBS). After another round of washing, peroxidase activity was detected using chemiluminescence (Super Signal West Pico; Pierce) and imaged using a Eastman Kodak (Rochester, NY) Image Station 1000.

\section{Results}

\section{Striatal LTD does not require presynaptic transcription but requires mRNA translation}

Using field potential recording, we showed that long-lasting LTD (duration $>150 \mathrm{~min}$ ) can be induced in the striatum-only slice preparation, suggesting that the removed presynaptic cell body is not needed for the induction and long-term maintenance of this form of LTD. As shown in Figure 1, when the amplitude of the baseline PS was compared with that of PS 20-30 min after HFS, a significant depression was observed (PS amplitude, $62 \pm 7 \%$ of baseline; $p<0.05 ; n=9$ slices from 9 rats). Previous work has shown that striatal LTD does not require NMDA receptor activation, but because NMDA receptor-dependent long-term potentiation (LTP) could also be found in the striatum, in some of the experiments, we used APV to prevent striatal LTP (Gerdeman et 

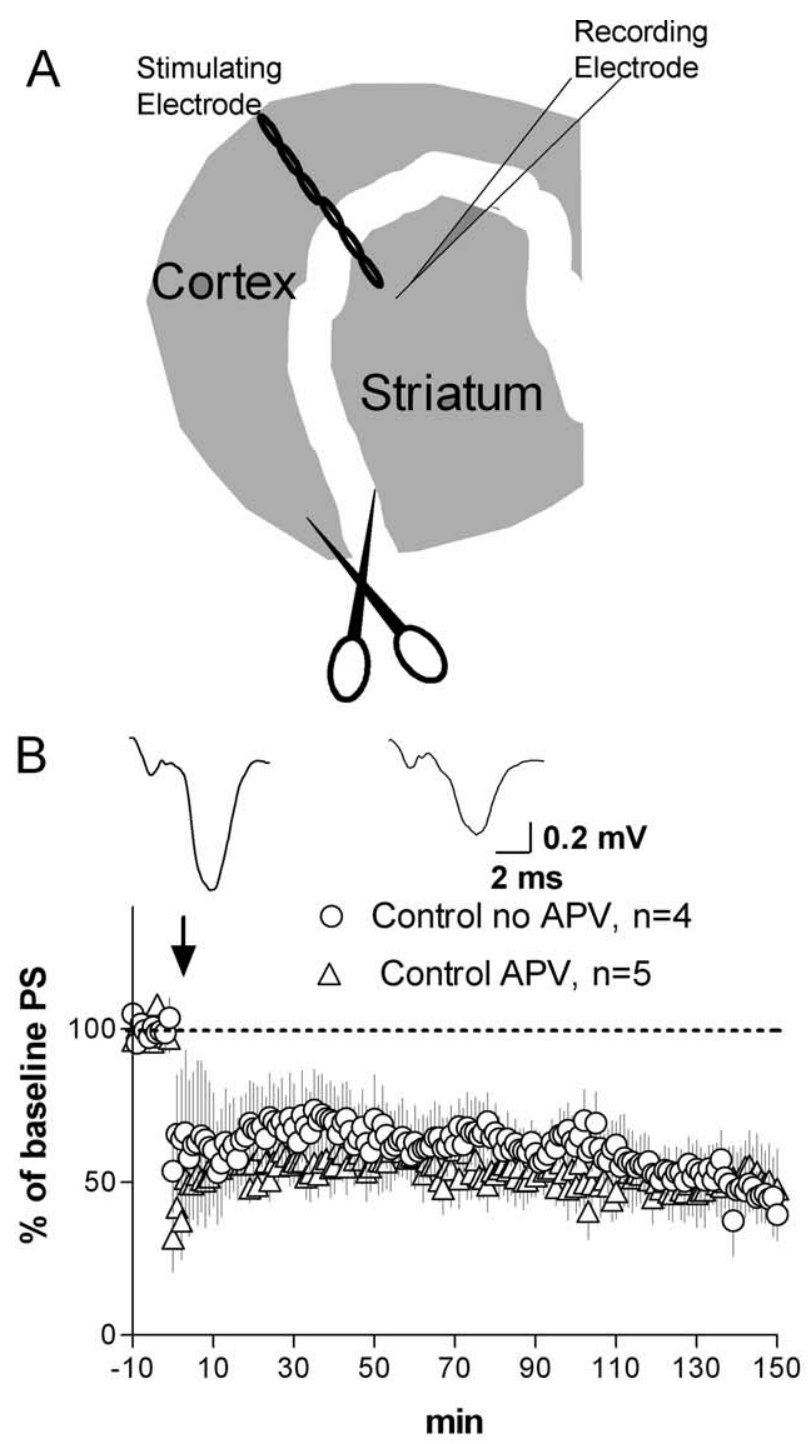

c
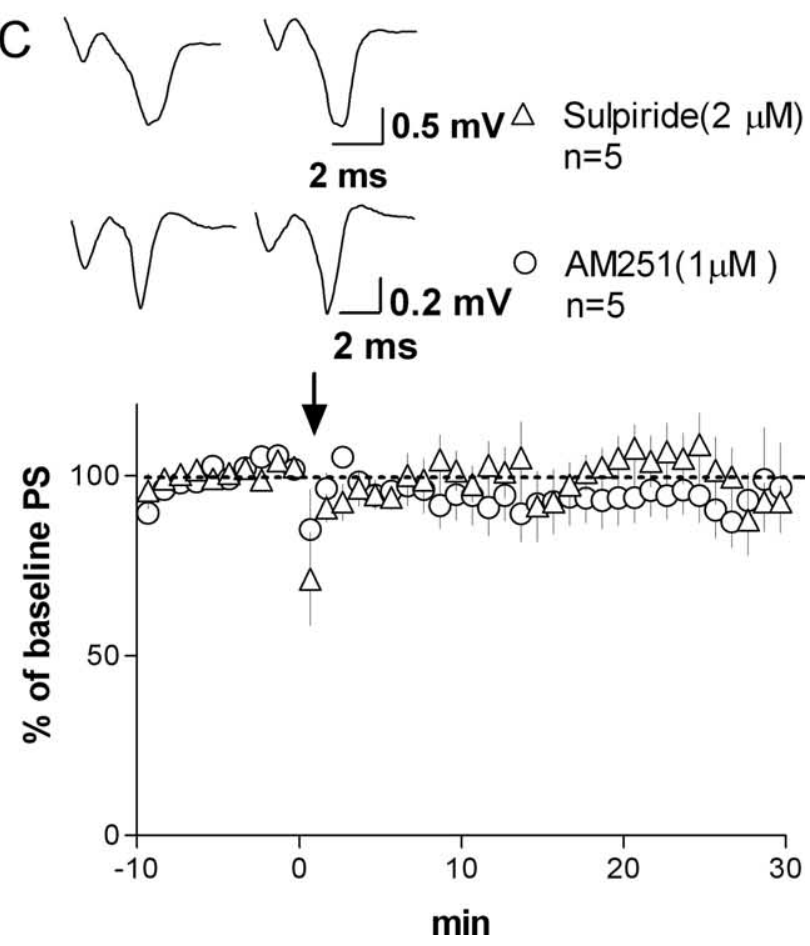

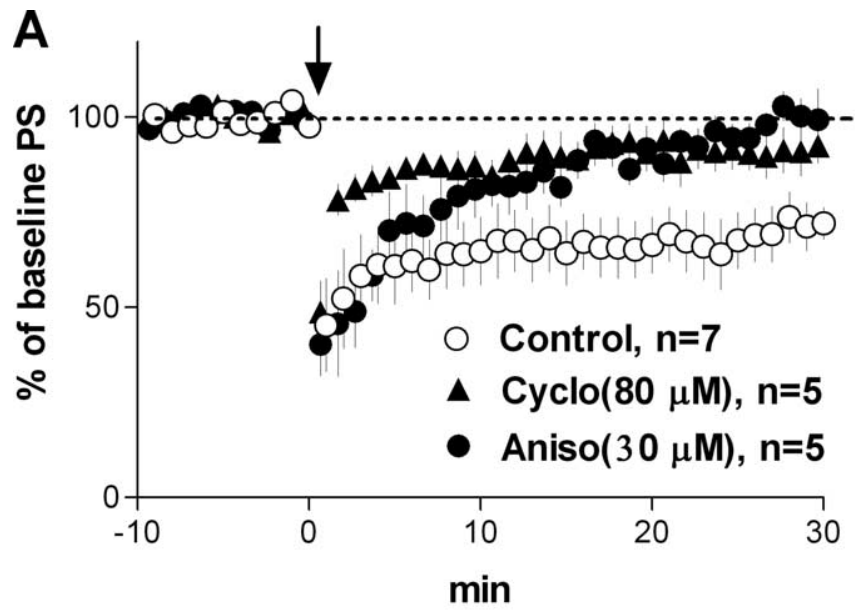

B

\section{Baseline After HFS}
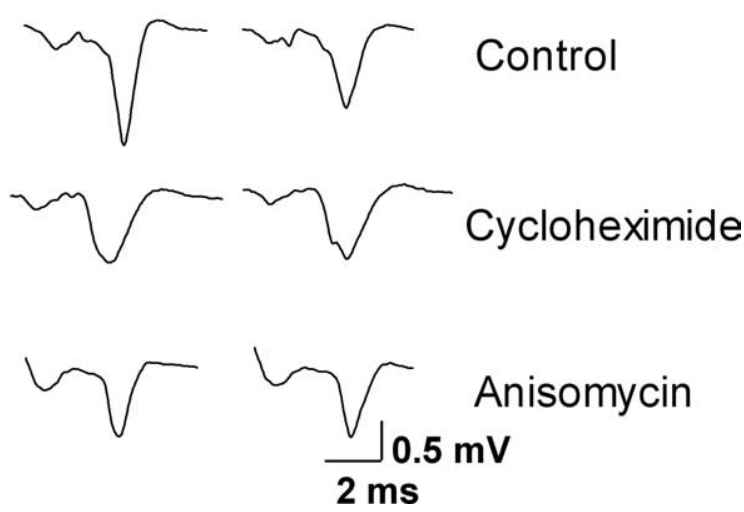

Figure 2. LTD in the striatum-only preparation requires mRNA translation. $A$, LTD is blocked by translation inhibitors cycloheximide (Cyclo) and anisomycin (Aniso). These drugs were present in the bath at least 10 min before recording. $\boldsymbol{B}$, Representative traces showing field PSS. Arrow indicates time of high-frequency stimulation.

al., 2002). However, because LTD was observed with or without 50 APV (selective NMDA receptor antagonist) in the bath, the data were combined for analysis.

Replicating previous findings (Gerdeman et al., 2002; Kreitzer and Malenka, 2005), we showed that this form of LTD requires dopamine $\mathrm{D}_{2}$ receptor activation as well as $\mathrm{CB}_{1}$ receptor activation. LTD was completely blocked by bath application of the $\mathrm{D}_{2}$ antagonist sulpiride ( $2 \mu \mathrm{M}$; PS amplitude, $101 \pm 6 \%$; $p>0.05$; $n=5$ slices from 2 rats $)$ or the $\mathrm{CB}_{1}$ antagonist AM251 [N-1-(2,4dichlorophenyl)-5-(4-iodophenyl)-4-methyl- $N$-1-piperidinyl$1 \mathrm{H}$-pyrazole-3-carboxamide] ( $1 \mu \mathrm{M}$; EPSC amplitude, $92 \pm 8 \%$; $p>0.05 ; n=5$ slices from 2 rats).

Moreover, striatal LTD requires protein translation, because it

Figure 1. LTD in the striatum-only preparation does not require the presynaptic cell body. All traces shown in the figures are averages of 10 sweeps. $A$, Schematic illustration of the striatumonly preparation. Both the stimulating and recording electrodes are placed in the dorsolateral striatum. $\boldsymbol{B}$, Long-lasting LTD (>150 $\mathrm{min}$ ) can be induced in the striatum-only preparation, as measured by the amplitude of population spikes. Agreeing with previous work on striatal LTD, blockade of NMDA receptors with APV had no effect on this form of plasticity. C, This form of LTD is blocked by sulpiride, $\mathrm{D}_{2}$ antagonist, or $\mathrm{AM} 251, \mathrm{a} \mathrm{CB}_{1}$ antagonist. Data are shown as percentage of baseline PS amplitude. Arrow indicates time of high-frequency stimulation (4 trains of $100 \mathrm{~Hz}$ stimulation $1 \mathrm{~s}$ in duration and $10 \mathrm{~s}$ apart). 
was also blocked by mRNA translation inhibitors $(80 \mu \mathrm{M}$ cycloheximide or $30 \mu \mathrm{M}$ anisomycin). As illustrated in Figure 2, control slices showed significant depression (PS amplitude, $71 \pm 6 \% ; p<0.05$; $n=7$ slices from 7 rats), whereas slices treated with cycloheximide (PS amplitude, $91 \pm 6 \% ; p>0.05 ; n=5$ slices from 5 rats) or anisomycin (PS amplitude, $96 \pm 6 \%$; $p>0.05 ; n=5$ slices from 5 rats) did not show LTD. To assess the effect of translation inhibitors on synaptic transmission, an ANOVA was performed on baseline PS amplitudes (control, $1.22 \pm 0.27 \mathrm{mV}$; cycloheximide, $0.84 \pm 0.22 \mathrm{mV}$; anisomycin, $0.68 \pm 0.05 \mathrm{mV}$ ) using treatment group as a between-subjects factor. No effect of group was found $\left(F_{(2,14)}=1.9 ; p>0.05\right)$. Thus, synthesis inhibitors appeared only to affect LTD in these experiments.

\section{Striatal LTD does not require} translation in the postsynaptic cell Because DLS-LTD is expressed presynaptically, the above observation suggests the intriguing possibility that the protein synthesis involved could take place locally. Because previous work has implicated postsynaptic translation in long-term synaptic plasticity (Huber et al., 2000; Huang et al., 2005), it is important to examine possible involvement of postsynaptic translation in striatal LTD.

Using whole-cell recording, we further investigated the site of protein synthesis necessary for LTD. We compared effects of bath application of cycloheximide $(80 \mu \mathrm{M})$ with postsynaptic intracellular loading of this translation inhibitor at the same concentration (Fig. $3 A, B$ ). In agreement with observations from our field potential recording experiments, HFS resulted in long-lasting depression of EPSC amplitude in control slices (EPSC amplitude, $75 \pm 3 \% ; p<0.05 ; n=11$ cells from 10 rats) (Fig. $3 A$ ); there was also a significant increase in PPR (second EPSC divided by first EPSC) (Fig. 3D), which indicates a reduction in the probability of presynaptic glutamate release, thus confirming the presynaptic site of expression for this form of plasticity (baseline PPR, $1.02 \pm 0.05 ; 20-30$ min after HFS PPR, $1.12 \pm 0.05 ; p<0.05)$. When cycloheximide $(80 \mu \mathrm{M})$ was applied 20-30 min before HFS (EPSC amplitude, $106 \pm 8 \%$; $p>0.05$; baseline PPR, $1.05 \pm 0.04 ; 20-30 \mathrm{~min}$ after HFS PPR, $1.09 \pm$ $0.07 ; p>0.05 ; n=7$ cells from 6 rats) or immediately after HFS (EPSC amplitude, $95 \pm 3 \%, p>0.05$; baseline PPR, $1.09 \pm 0.06$; 20-30 min after HFS PPR, $1.16 \pm 0.07, p>0.05 ; n=10$ slices from 6 rats), no LTD or increased PPR was observed. In contrast, cycloheximide at the same concentration loaded into the postsynaptic neuron did not impair LTD (EPSC amplitude, $84 \pm$ $4 \% ; p<0.05$; baseline PPR, $1.06 \pm 0.03 ; 20-30$ min after HFS PPR, $1.16 \pm 0.03 ; p<0.05 ; n=10$ slices from 6 rats), indicating that protein synthesis in the postsynaptic cell is not necessary for

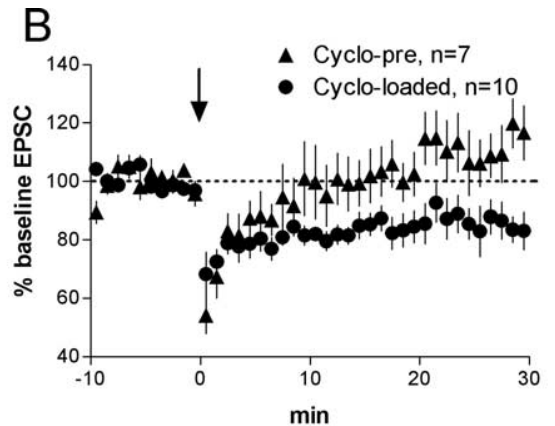

Baseline After HFS
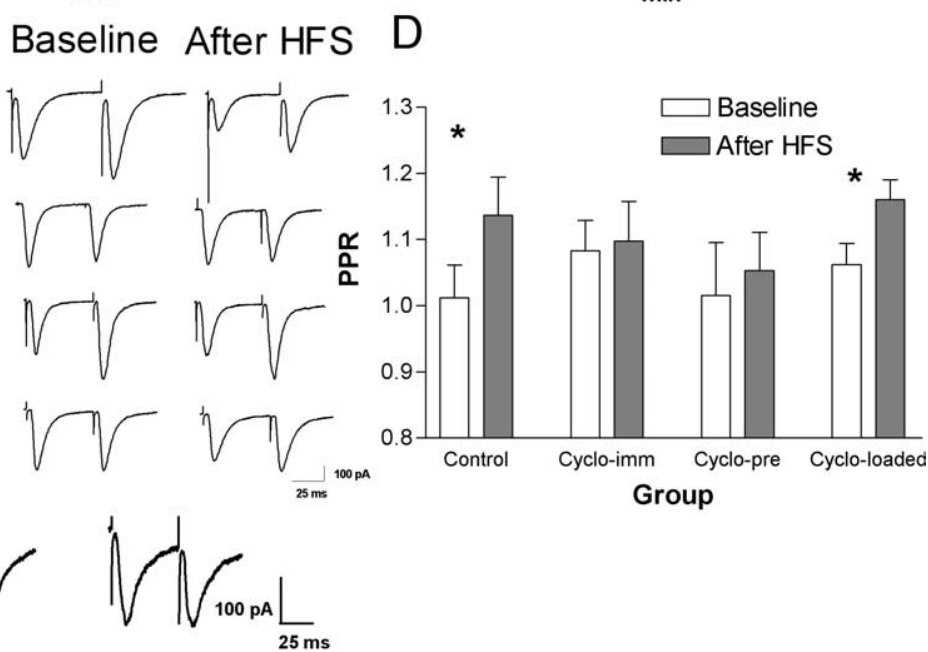

Group

Figure 3. Postsynaptic mRNA translation is not necessary for striatal LTD. $\boldsymbol{A}$, Cycloheximide (Cyclo) (80 $\mu \mathrm{m})$ applied to the extracellular bath solution immediately after HFS blocks striatal LTD. B, Cycloheximide applied to the bath $20-30 \mathrm{~min}$ ing a presynaptic site of expression. $\boldsymbol{E}$, Bath application of cycloheximide after $20 \mathrm{~min}$ of stable baseline recording does not alter EPSC amplitude in the absence of an LTD-inducing stimulus. ${ }^{*} p<0.05$. Arrow indicates time of high-frequency stimulation and postsynaptic depolarization to $0 \mathrm{mV}$.

LTD (Fig. 3B). Finally, we demonstrated that bath application of cycloheximide has no effect on synaptic transmission in the absence of LTD induction (no difference in EPSC amplitude between baseline responses and responses 5-20 min after bath application of $80 \mu \mathrm{M}$ cycloheximide; $p>0.05 ; n=10$ cells from 4 rats) (Fig. $3 E$ ). It is also worth noting that PPR values observed before high-frequency stimulation in experiments with protein synthesis inhibitors did not differ from values in untreated slices. Thus, these inhibitors do not appear to alter baseline release probability, and the effects on LTD are not a consequence of altered glutamatergic drive onto MSNs or occlusion of the LTD expression mechanism.

Because LTD has been shown to require retrograde endocannabinoid signaling and activation of $\mathrm{CB}_{1}$ receptors (Gerdeman et al., 2002), it is possible that cycloheximide could prevent LTD 

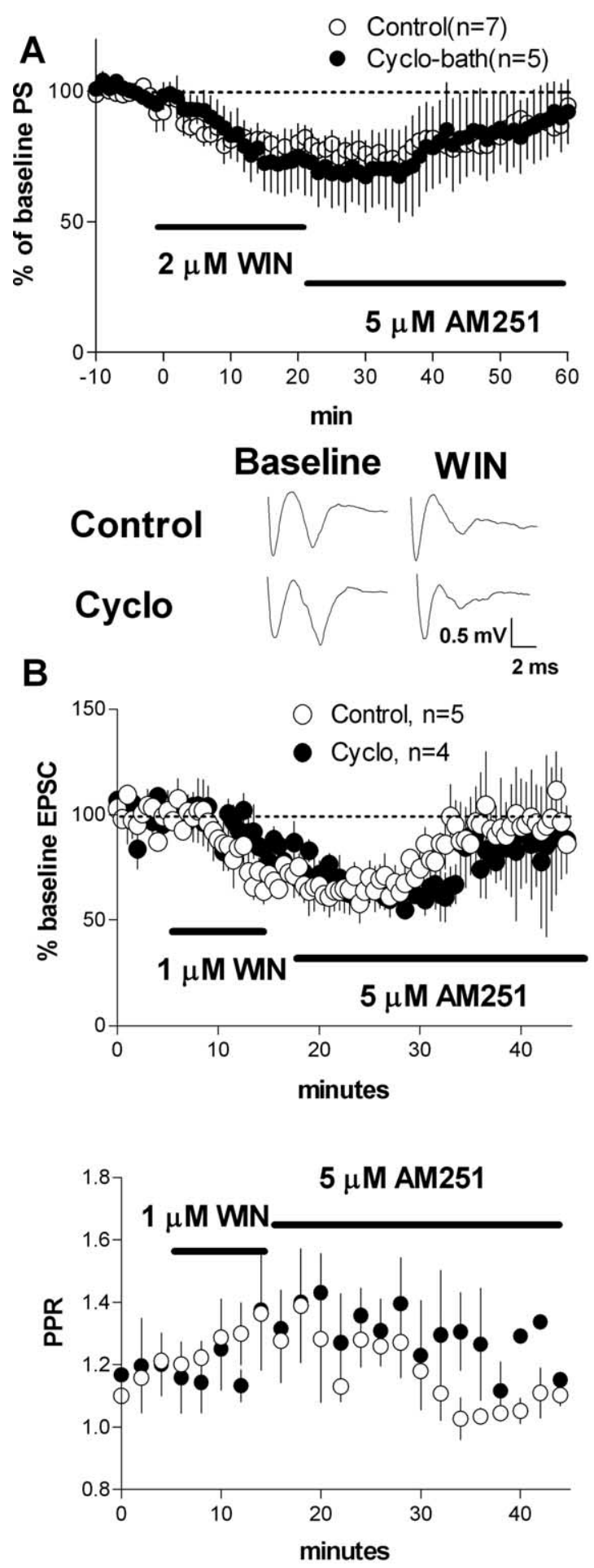

\section{Baseline WIN}

Control

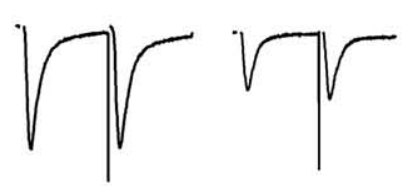

Cyclo

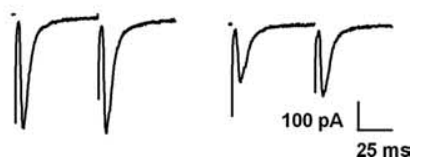

simply by disrupting $\mathrm{CB}_{1}$-mediated signaling rather than by inhibiting protein synthesis. Previous research showed that the activation of $\mathrm{CB}_{1}$ receptors alone is not sufficient to induce LTD but rather causes depression that can be reversed by a $\mathrm{CB}_{1}$ receptor antagonist (Ronesi et al., 2004). To test this possibility, we examined the effects of cycloheximide on $\mathrm{CB}_{1}$ receptor-mediated inhibition of glutamatergic transmission at the corticostriatal synapse (Gerdeman and Lovinger, 2001; Ronesi et al., 2004). As shown in Figure $4 \mathrm{~A}$, in control slices, bath application of the $\mathrm{CB}_{1}$ agonist WIN 55,212-2 $[R-(+)$-(2,3-dihydro-5-methyl-3-[(4morpholinyl)methyl]pyrol[1,2,3-de]-1,4- benzoxazin-6-yl)(1naphthalenyl) methanone monomethanesulfonate] $(2 \mu \mathrm{M})$ significantly reduced population spike amplitude in the DLS (PS amplitude, $78 \pm 4 \%$ of baseline; $p<0.05 ; n=7$ slices from 7 rats), and this inhibition was reversed by the $\mathrm{CB}_{1}$ antagonist AM251 $(5 \mu \mathrm{M})$. This finding replicates results from a previous study (Ronesi et al., 2004). The application of $\mathrm{CB}_{1}$ agonist alone is not sufficient to induce LTD, although the reversal by antagonist application took place very slowly, with considerable variability. More important for present purposes, however, was the observation of a similar reversible inhibition in slices treated with cycloheximide $(80 \mu \mathrm{M})$ during baseline recording and the application of WIN 55,212-2 (PS amplitude, $70 \pm 12 \%$ of baseline; $p<0.05$; $n=5$ slices from 4 rats). Cycloheximide therefore did not appear to have any effect on endocannabinoid signaling required for reversible, presynaptically expressed depression.

Although our field recording data replicated those from a previous study, they do not agree with recent results obtained by Kreitzer and Malenka (2005). Using whole-cell recording, these investigators found that bath application of WIN 55,212-2 resulted in long-lasting and irreversible depression, i.e., that the activation of $\mathrm{CB}_{1}$ receptors at the presynaptic terminal is sufficient to induce LTD. Such a difference could be attributed to the difference in the recording techniques used. To address this issue, we performed the same experiment using whole-cell recording. Again replicating our field recording data, we found that activation of $\mathrm{CB}_{1}$ receptors results in a reduction in the EPSC amplitude and PPR in both the control and cycloheximide-treated slices (control, EPSC amplitude, $61 \pm 7 \%$ of baseline; $p<0.05$; $n=5$ cells from 4 rats; cycloheximide, EPSC amplitude, $62 \pm 7 \%$ of baseline; $p<0.05 ; n=4$ cells from 4 rats), and this inhibition was reversed by the $\mathrm{CB}_{1}$ antagonist AM251 (5 $\left.\mu \mathrm{M}\right)$ in slices from both treatment groups (Fig. $4 B$ ).

Having established that the effect of cycloheximide on striatal LTD is not a result of its effects on synaptic transmission or $\mathrm{CB}_{1}$ receptor-mediated signaling, we next assessed the role of transcription in striatal LTD. We loaded the transcription inhibitor actinomycin $\mathrm{D}(20 \mu \mathrm{M})$ into the postsynaptic cell or applied it to the bath. As shown in Figure 5A, control cells showed LTD (EPSC amplitude, $68 \pm 2 \%$ of baseline; $p<0.05$; baseline PPR, $1.1 \pm$ $0.04 ; 20-30$ min after HFS PPR, $1.22 \pm 0.1 ; p<0.05 ; n=5$ cells from 5 rats). Actinomycin D, either loaded into the postsynaptic cell (EPSC amplitude, $71 \pm 5 \%$ of baseline; $p<0.05 ; n=7$ cells from 5 rats) or applied to the bath (EPSC amplitude, $69 \pm 2 \%$ of

\footnotetext{
Figure 4. Cycloheximide does not disrupt $\mathrm{CB}_{1}$-mediated inhibition of excitatory transmission. $\boldsymbol{A}$, Cycloheximide (Cyclo) does not affect WIN 55,212-2 (WIN)-induced depression. For both control slices and cycloheximide-treated slices, a reversible depression was observed after bath application of WIN 55,212-2, followed by AM251. For the cycloheximide-treated slices, the drug was in the bath for at least $10 \mathrm{~min}$ before recording and was present throughout the recording. $\boldsymbol{B}$, Replication of the field potential recording results using whole-cell patch-clamp recording. A transient reduction in PPR was observed after bath application of WIN 55,212-2.
} 

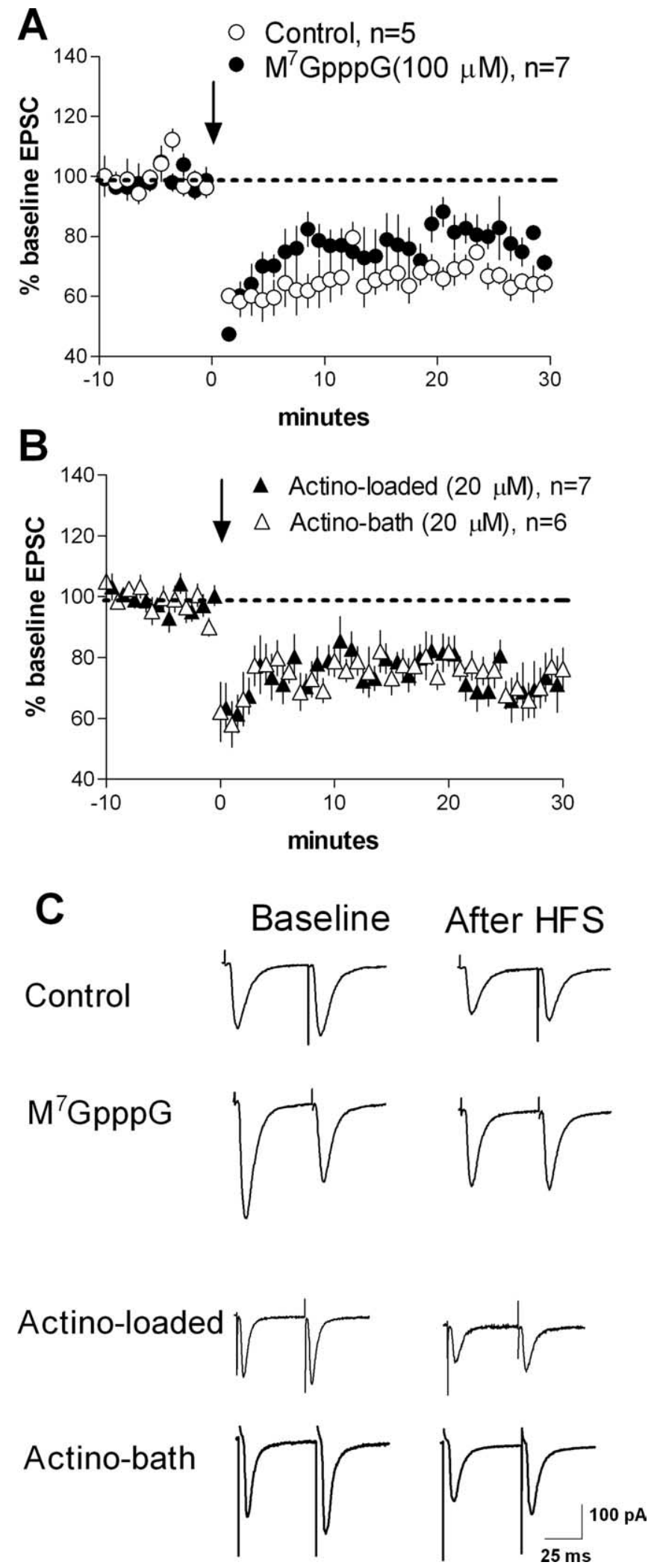

Figure 5. Postsynaptic loading of actinomycin $D$ or $M^{7} G p p p G$ did not block striatal LTD. $\boldsymbol{A}$, $M^{7} \mathrm{GpppG}$, an RNA cap analog that blocks translation by competing with endogenous RNA for binding to the initiation factor, did not prevent LTD when loaded into the postsynaptic cell. $\boldsymbol{B}$ Intracellular loading or bath application of actinomycin D (Actino), a transcription inhibitor, did not block striatal LTD. Arrow indicates time of high-frequency stimulation and postsynaptic depolarization to $0 \mathrm{mV}$. baseline; $p<0.05 ; n=6$ cells from 2 rats), did not prevent striatal LTD. To further rule out any role for postsynaptic translation, we also used a different translation inhibitor: $\mathrm{M}^{7} \mathrm{GpppG}$, an RNA cap analog that blocks translation by competing with endogenous RNA for binding to the initiation factor. This treatment also failed to block striatal LTD (EPSC amplitude, $77 \pm 6 \%$ of baseline; $p>0.05$; baseline PPR, $1.11 \pm 0.04 ; 20-30$ min after HFS PPR, $1.37 \pm 0.07 ; n=7$ cells from 5 rats) (Fig. $5 A$ ).

Striatal LTD requires the activation of mGluRs (Calabresi et al., 1992b; Choi and Lovinger, 1996), and thus cycloheximide could disrupt LTD by interfering with mGluR signaling in striatal neurons. Kreitzer and Malenka (2005) recently showed that striatal LTD can be induced by the mGluR agonist DHPG alone when the MSN is clamped at a depolarized potential $(-50 \mathrm{mV})$, which allows additional signaling by voltage-gated L-type calcium channels. We replicated this finding in our striatum-only preparation (Fig. 6) and found that DHPG/depolarization reduced EPSC amplitude. The initial reduction in the EPSC measured 5 min after beginning agonist application was similar in control slices and slices treated with cycloheximide. However, whereas agonist treatment induced LTD in the control group, the response returned to baseline amplitude $\sim 20$ min after the onset of agonist treatment (10 $\mathrm{min}$ after agonist washout) in cycloheximide-treated slices (EPSC amplitude 20-30 min after agonist application, control, $79 \pm 3 \%$ of baseline; $p<0.05 ; n=8$ cells from 4 rats; cycloheximide, $93 \pm 3 \% ; n=9$ cells from 4 rats). These findings indicate that translation inhibition does not alter mGluR signaling but prevents LTD-inducing signaling downstream of mGluR activation.

As an additional control for cycloheximide effects on mGluRmediated signaling, we directly measured mGluR-mediated synaptic current in the medium spiny neurons from DLS. Slow EPSCs (duration $\sim 500 \mathrm{~ms}$ ) were induced by trains of 10 stimuli applied within the striatum in the presence of blocker of fast, ionotropic receptor-mediated responses (50 $\mu \mathrm{M}$ picrotoxin, 50 $\mu \mathrm{M}$ APV, and $20 \mu \mathrm{M} \mathrm{NBQX).} \mathrm{This} \mathrm{current} \mathrm{was} \mathrm{significantly} \mathrm{re-}$ duced by combined application of the mGluR 1 antagonist CPCCOEt and the mGluR5 antagonist MPEP, confirming that it was mediated by group I mGluRs ( $p<0.05 ; n=5$ cells from 3 rats) (Fig. 6B). Cycloheximide, however, had no effect on mGluRmediated current ( $p>0.05 ; n=6$ cells from 3 rats) (Fig. $6 C$ ).

To confirm that postsynaptic loading of cycloheximide can sufficiently reduce protein synthesis necessary for long-term plasticity, we conducted a positive control experiment examining a different form of LTD in the CA1 region of the hippocampus. This form of LTD, known to require protein synthesis in the postsynaptic cell (in rats that are P21 and older), is also induced by DHPG application (Huber et al., 2000; Nosyreva and Huber, 2005). If intracellular loading of cycloheximide was sufficient to inhibit protein synthesis postsynaptically, then it should also block DHPG-induced LTD in the hippocampus. This was indeed what we observed (Fig. 7). Robust LTD was induced by DHPG in the hippocampus (EPSC amplitude, $67 \pm 6 \%$ of baseline; $p<$ $0.05 ; n=6$ cells from 6 rats). However, intracellular loading of cycloheximide $(80 \mu \mathrm{M})$ blocked this form of LTD $(105 \pm 13 \%$ of baseline; $p>0.05 ; n=5$ cells from 4 rats). Thus, intracellular loading of cycloheximide was effective in blocking postsynaptically expressed LTD that requires postsynaptic protein synthesis. Note, however, that although cycloheximide blocks LTD, it does not affect short-term depression induced by DHPG; it has no significant effect on transient depression (5-10 min after application) caused by DHPG signaling but abolishes the mRNA translation required for DHPG-induced LTD, reinforcing the 

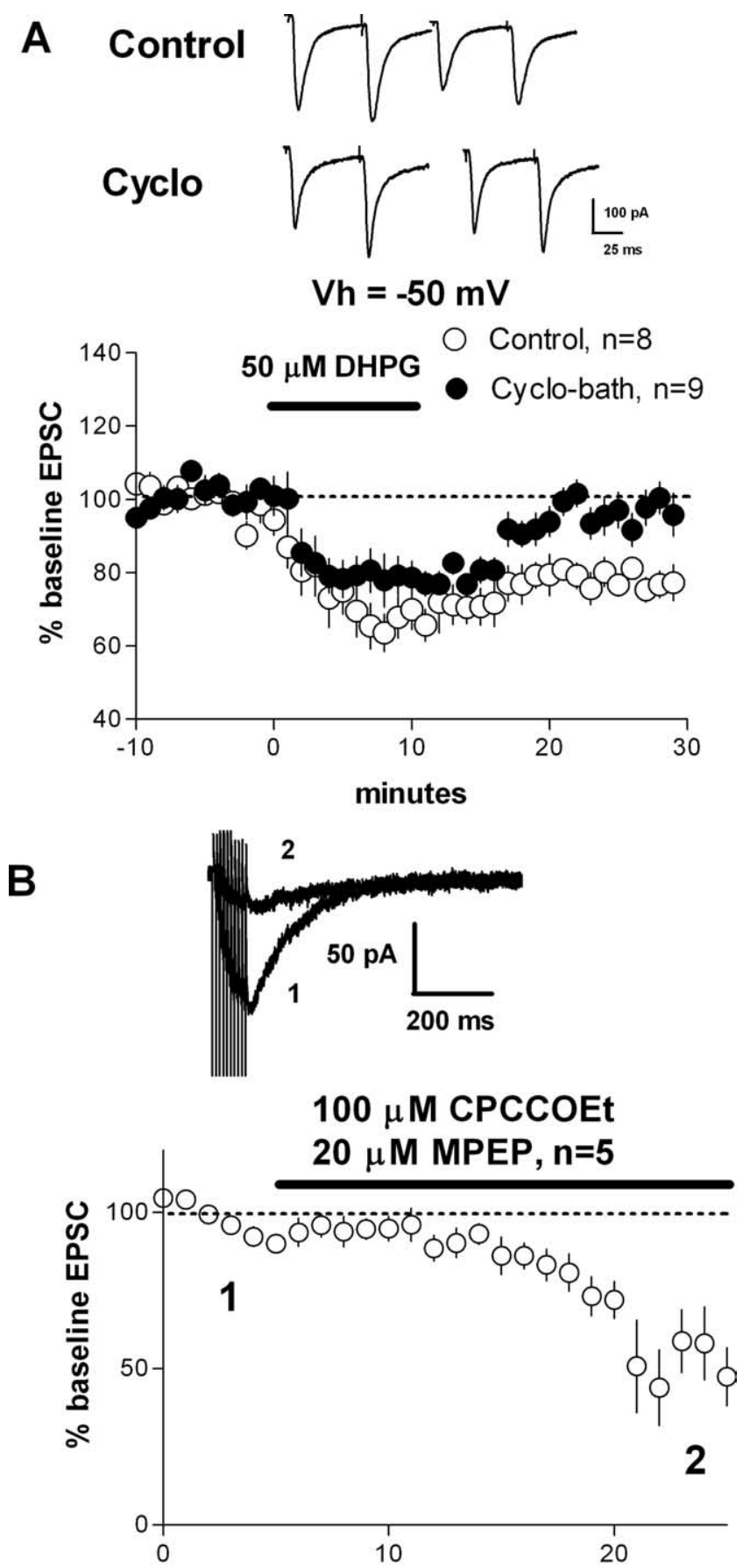

C

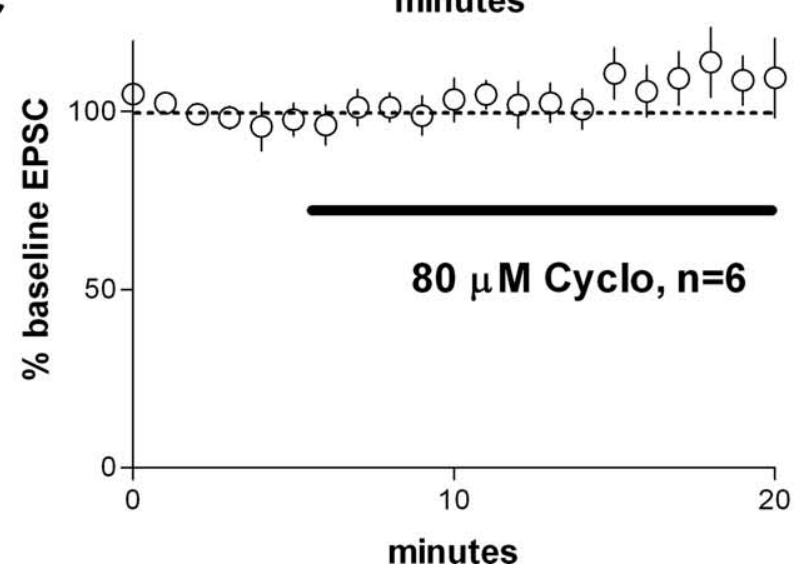

\section{Baseline After DHPG}

\section{Control}
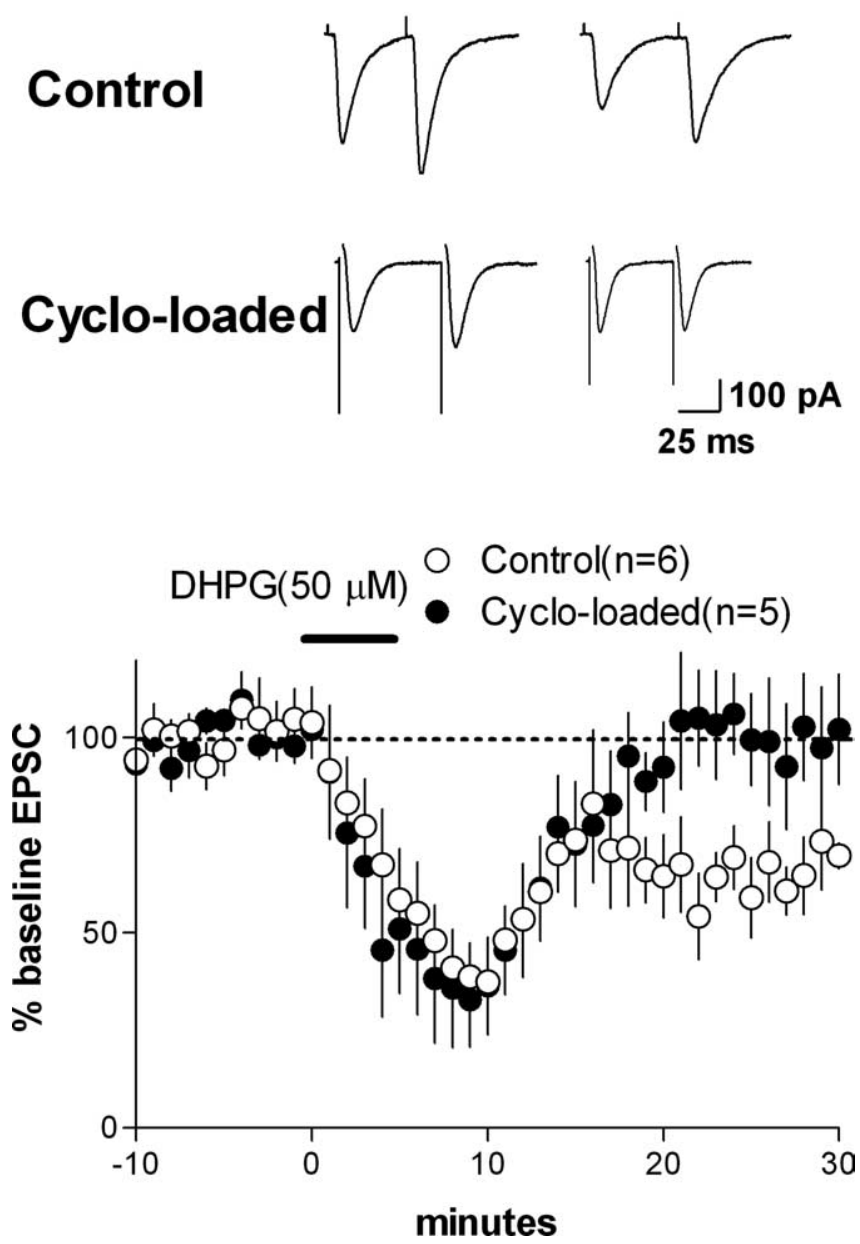

Figure 7. Postsynaptically expressed hippocampal LTD induced by DHPG is blocked by intracellular loading of cycloheximide. LTD at the CA1 synapse can be induced with 5 min application of $50 \mu \mathrm{M} \mathrm{DHPG}$, but this form of LTD is blocked by intracellular loading of $80 \mu \mathrm{m}$ cycloheximide (Cyclo). Top, Representative EPSC traces. Bottom, Graph showing normalized EPSC amplitude as a function of time before, during, and after DHPG application in control and cycloheximidetreated slices. Note that cycloheximide has no effect on DHPG suppression of EPSC amplitude at $10 \mathrm{~min}$ after agonist onset but blocks LTD at the $30 \mathrm{~min}$ time point.

conclusion that cycloheximide does not act by inhibiting mGluR signaling.

Cycloheximide is effective in inhibiting translation Finally, to ensure that translation inhibitors could suppress protein production within the time frame used in our experiments and to assess the extent of protein synthesis inhibition by bath application of cycloheximide to the brain slice, we examined the effects of cycloheximide treatment on protein synthesis. Synthe-

Figure 6. Bath application of cycloheximide does not interfere with mGluR function but blocks DHPG-induced LTD in the striatum. $\boldsymbol{A}$, Graph showing normalized EPSC amplitude as a function of time before, during, and after DHPG application in control and cycloheximide (Cyclo)-treated slices. Note that cycloheximide has no effect on DHPG suppression of EPSC amplitude at $10 \mathrm{~min}$ after agonist onset but blocks LTD at the $30 \mathrm{~min}$ time point. $\boldsymbol{B}$, Representative trace of the mGluR-mediated synaptic current in the DLS recorded in the absence and presence of group I mGluR antagonists CPCCOEt and MPEP, as indicated. This current is significantly reduced by bath application of the mGluR antagonists. C, Graph showing that the mGluRmediated synaptic current is not affected by bath application of cycloheximide. 


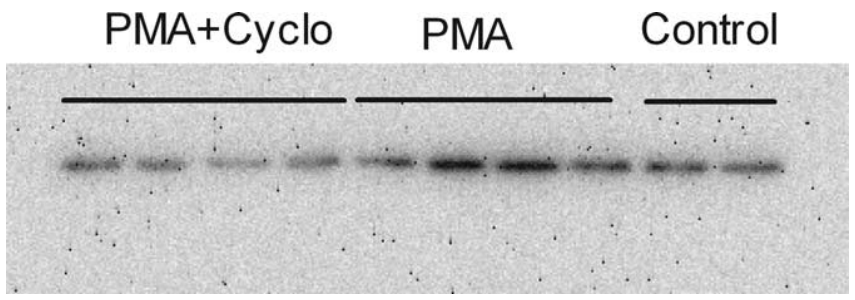

Figure 8. Effect of cycloheximide treatment on PMA-induced c-Fos synthesis in the brain slice. Coronal corticostriatal sections were incubated in aCSF (control), treated with $1 \mu \mathrm{M}$ PMA for $30 \mathrm{~min}$, or pretreated with $80 \mu \mathrm{m}$ cyloheximide for $30 \mathrm{~min}$ and then treated with $1 \mu \mathrm{M}$ PMA for another $30 \mathrm{~min}$ (PMA\&Cyclo). Net intensity values were normalized to controls for each blot.

sis of the immediate early gene c-Fos induced by PMA was examined in these experiments because this protein is produced in a rapid manner, allowing examination of inhibitor effects on the desired timescale. First, we showed that cycloheximide $(80 \mu \mathrm{M})$ alone does not significantly reduce c-Fos expression ( $95 \pm 4 \%$ of control; $p>0.05 ; n=6$ ). However, as shown in Figure 8 , when PMA $(1 \mu \mathrm{M})$ was added to the bath solution for $30 \mathrm{~min}$, the expression of c-Fos in the brain slice was significantly enhanced (160 $\pm 7 \%$ of control; $p<0.05 ; n=8)$, and this enhancement was prevented by pretreatment with cycloheximide for $30 \mathrm{~min}$ $(91 \pm 12 \%$ of control; $p>0.05 ; n=8)$. These results demonstrate the efficacy of cycloheximide as an inhibitor of protein synthesis in the brain slice.

\section{Discussion}

In this study, we demonstrated that a presynaptically expressed form of LTD in the striatum can be induced without the cell body of the presynaptic neuron. Transcription in the presynaptic cell nucleus is therefore not necessary for the expression and maintenance (duration $>150 \mathrm{~min}$ ) of striatal LTD. Actinomycin D, a transcription inhibitor, had no effect on striatal LTD whether applied to the bath or loaded into the postsynaptic cell (Fig. 5). This form of LTD, however, requires protein translation, because it was blocked by inhibitors of mRNA translation.

Such a finding raises the question of where the requisite translation takes place. We showed that bath application of cycloheximide, a translation inhibitor, blocks striatal LTD induced by HFS (Fig. 3) or by prolonged activation of group I mGluRs with DHPG (Fig. 6). Using intracellular loading with the patch pipette, we also showed that inhibition of translation in the postsynaptic cell did not block striatal LTD, although the same treatment blocked a different form of LTD in the hippocampus. The latter experiment demonstrates that cycloheximide is easily loaded into the postsynaptic neuron, and we know from past studies that larger molecules, such as Alexa Fluor 594, can be loaded easily into medium spiny neurons via the patch pipette (Wang et al., 2006). Thus, the lack of effect of postsynaptic cycloheximide loading on striatal LTD is not likely attributable to the inability of the drug to reach the relevant sites in the postsynaptic neuron. By measuring the level of a rapidly synthesized protein in the slice with Western blotting, we also showed that bath application of cycloheximide, at the dose used in our experiments, effectively inhibits mRNA translation in the slice preparation.

Together, these results show that the maintenance of a presynaptically expressed form of long-term plasticity is independent of transcription and that it does not require postsynaptic translation. This finding is to our knowledge the first piece of evidence ruling out transcription in both presynaptic and postsynaptic neurons as well as translation in the postsynaptic neuron in any form of mammalian long-term plasticity. It has important implications for our understanding of the molecular mechanisms underlying synaptic plasticity.

The blockade of striatal LTD does not appear to be a result of nonspecific effects of the translation inhibitors. We observed similar loss of LTD with two different inhibitors, anisomycin and cycloheximide. We also observed that cycloheximide had no effect on baseline synaptic transmission (Fig. 3E) and group I mGluR-mediated currents (Fig. 6B), nor did it alter short-term depression caused by DHPG (Fig. 6) or the reversible inhibition of glutamate release caused by $\mathrm{CB}_{1}$ activation (Fig. 4 ). Because the postsynaptic loading of translation inhibitors (cycloheximide and $M^{7} G$ pppG) did not block striatal LTD, these drugs do not appear to affect intracellular postsynaptic processes required for this form of plasticity, such as increases in intracellular calcium (Gerdeman et al., 2003). Because cycloheximide prevents LTD produced by HFS or DHPG, its effects are probably restricted to the mechanisms involved in LTD maintenance. Moreover, because the short-term depression induced by DHPG appears to require L-type channel activation (Kreitzer and Malenka, 2005), the lack of effect of cycloheximide on this depression indicates that the inhibitor does not act via inhibition of this calcium channel, which is critical for LTD induction. In light of these findings and the observation of a relatively slowly decaying form of synaptic depression in the presence of translation inhibitors, translation appears to be involved in the maintenance of striatal LTD.

Our data suggest the transected presynaptic axon as a possible site of mRNA translation for striatal LTD. Although, given technological limitations, we were not able to observe axonal translation in the brain slice directly, our experiments ruled out the presynaptic cell body and the postsynaptic cell as sites of translation, leaving the presynaptic axon as the most likely candidate. It should be noted, however, that a possible role of glial cells cannot be ruled out. Astrocytes, for example, are capable of synthesizing proteins involved in synaptic plasticity (Lewis and Teyler, 1986; Nishiyama et al., 2002). Because striatal LTD is initiated by $\mathrm{CB}_{1}$ receptor-mediated signaling, any contribution by glial cells would probably have to take place downstream of the receptor. In addition, translation taking place in striatal neurons other than the medium spiny neurons could also contribute to LTD. Although unlikely given available evidence, these possibilities remain to be explored.

\section{Possible role of local axonal translation}

Caveats aside, an intriguing hypothesis can be formulated on the basis of our results: in the axons of cortical neurons (and possibly also axons from the intralaminar thalamic nuclei, a less prominent sources of excitatory inputs to the DLS), proteins that regulate glutamate release could be translated locally and rapidly in response to retrograde endocannabinoid signaling caused by HFS. The time course over which EPSC amplitude returned to baseline levels when cycloheximide was applied either 20-30 min before or immediately after HFS (Fig. $3 A, B$ ) indicates that translated proteins begin to play a role in reducing glutamate release within $\sim 10 \mathrm{~min}$ after tetanic stimulation. That the required proteins, in response to physiological signals, could be translated and folded in such a short period of time is not surprising. For instance, previous work (Li et al., 2004) has shown that such a time course is plausible, because semaphorin $3 \mathrm{~A}$, a secreted guidance cue for growth cones, can enhance the level of phosphorylated eukaryotic translation initiation factor $4 \mathrm{E}$ within $5 \mathrm{~min}$ of its application to cultured cells.

At the presynaptic terminal, translation could be initiated by 
the activation of $\mathrm{CB}_{1}$ receptors, which are abundantly expressed there. $\mathrm{CB}_{1}$ receptors mediate short-term forms of synaptic plasticity such as depolarization-induced suppression of inhibition and depolarization-induced suppression of excitation (Alger, 2002). For striatal LTD, however, $\mathrm{CB}_{1}$ receptor activation is only required for induction and not for long-term maintenance (Ronesi et al., 2004). Tetanic stimulation that induces LTD apparently triggers a process that interacts with $\mathrm{CB}_{1}$ receptor activation to result in a long-lasting reduction in the probability of glutamate release. Neither the pathway from $\mathrm{CB}_{1}$ receptor activation to local protein synthesis nor the identity of the proteins involved is currently known.

Our findings provide additional support for the claim that $\mathrm{CB}_{1}$ receptor activation alone is not sufficient to induce LTD. Application of $\mathrm{CB}_{1}$ antagonist reliably reversed agonist-induced inhibition in both field potential and whole-cell recordings (Fig. 4). It is not clear why Kreitzer and Malenka (2005) did not observe this antagonist effect, but the apparent discrepancy in these findings may be explained by a combination of factors commonly encountered in slice physiology when lipophilic drugs are applied to the bath, such as rate of solution exchange, recording chamber configuration, and length of recording before the response returns to baseline (which in this particular instance could be a very slow process). At any rate, our results indicate that $\mathrm{CB}_{1}$ receptor activation alone produces only translation-independent modulation of glutamatergic transmission that is distinguishable from LTD.

Although the role of dendritic protein translation in longterm plasticity is widely accepted, axons are not traditionally thought to be sites of protein synthesis (Huber et al., 2000; Martin, 2004; Huang et al., 2005; Tsokas et al., 2005). Strong evidence, however, has emerged in recent years showing local translation of proteins from existing mRNAs in the axon (Alvarez et al., 2000; Campenot and Eng, 2000; Piper and Holt, 2004). The only previously demonstrated role for axonal translation in synaptic plasticity is in the Aplysia (Martin et al., 1997; Sherff and Carew, 1999; Martin et al., 2000; Si et al., 2003), but, because the invertebrate axon is not as functionally specialized as the vertebrate axon, such work gives no indication of whether mammalian neurons, which have much more polarized processes, would also possess this capacity. In mammalian axons, currently established functional roles of axonal translation are restricted to growth cone guidance and regeneration after injury (Campbell and Holt, 2001; Zheng et al., 2001; Campbell and Holt, 2003; Willis et al., 2005). For example, in the process of finding their targets, growth cones must change responsiveness to guidance cues by local synthesis of cell surface receptors within the distal segment of the axon (Brittis et al., 2002). Likewise, after injury, regenerating axons are also the site of local mRNA translation of proteins normally involved in providing structural integrity of the growth cone (Zheng et al., 2001).

What all these phenomena and striatal LTD have in common is retrograde signaling, in which axons receive critical physiological signals fed back from their targets across the synapse. Axonal translation that takes place far away from the cell body would have the distinct advantage of immediate and spatially restricted response to such feedback from the postsynaptic cell, which circumvents the time-consuming and energetically expensive transport needed to move translated proteins from the cell body to the axon terminal. Although the detailed mechanisms involved in the long-term regulation of transmitter release remain essentially unknown, our results point to a potentially critical, although previ- ously neglected, role of such presynaptic processes in long-term synaptic plasticity in the mammalian brain.

\section{References}

Alger BE (2002) Retrograde signaling in the regulation of synaptic transmission: focus on endocannabinoids. Prog Neurobiol 68:247-286.

Alvarez J, Giuditta A, Koenig E (2000) Protein synthesis in axons and terminals: significance for maintenance, plasticity and regulation of phenotype. With a critique of slow transport theory. Prog Neurobiol 62:1-62.

Brittis PA, Lu Q, Flanagan JG (2002) Axonal protein synthesis provides a mechanism for localized regulation at an intermediate target. Cell 110:223-235.

Calabresi P, Maj R, Mercuri NB, Bernardi G (1992a) Coactivation of D1 and D2 dopamine receptors is required for long-term synaptic depression in the striatum. Neurosci Lett 142:95-99.

Calabresi P, Maj R, Pisani A, Mercuri NB, Bernardi G (1992b) Long-term synaptic depression in the striatum: physiological and pharmacological characterization. J Neurosci 12:4224-4233.

Campbell DS, Holt CE (2001) Chemotropic responses of retinal growth cones mediated by rapid local protein synthesis and degradation. Neuron 32:1013-1026.

Campbell DS, Holt CE (2003) Apoptotic pathway and MAPKs differentially regulate chemotropic responses of retinal growth cones. Neuron 37:939-952.

Campenot RB, Eng H (2000) Protein synthesis in axons and its possible functions. J Neurocytol 29:793-798.

Choi S, Lovinger DM (1996) Metabotropic glutamate receptor modulation of voltage-gated $\mathrm{Ca}^{2+}$ channels involves multiple receptor subtypes in cortical neurons. J Neurosci 16:36-45.

Choi S, Lovinger DM (1997) Decreased probability of neurotransmitter release underlies striatal long-term depression and postnatal development of corticostriatal synapses. Proc Natl Acad Sci USA 94:2665-2670.

Cromwell HC, Berridge KC (1996) Implementation of action sequences by a neostriatal site: a lesion mapping study of grooming syntax. J Neurosci 16:3444-3458.

Gerdeman G, Lovinger DM (2001) CB1 cannabinoid receptor inhibits synaptic release of glutamate in rat dorsolateral striatum. J Neurophysiol 85:468-471.

Gerdeman GL, Ronesi J, Lovinger DM (2002) Postsynaptic endocannabinoid release is critical to long-term depression in the striatum. Nat Neurosci 5:446-451.

Gerdeman GL, Partridge JG, Lupica CR, Lovinger DM (2003) It could be habit forming: drugs of abuse and striatal synaptic plasticity. Trends Neurosci 26:184-192.

Graybiel AM (1998) The basal ganglia and chunking of action repertoires. Neurobiol Learn Mem 70:119-136.

Huang F, Chotiner JK, Steward O (2005) The mRNA for elongation factor lalpha is localized in dendrites and translated in response to treatments that induce long-term depression. J Neurosci 25:7199-7209.

Huber KM, Kayser MS, Bear MF (2000) Role for rapid dendritic protein synthesis in hippocampal mGluR-dependent long-term depression. Science 288:1254-1257.

Joel D, Weiner I (2000) The connections of the dopaminergic system with the striatum in rats and primates: an analysis with respect to the functional and compartmental organization of the striatum. Neuroscience 96:451-474.

Jog MS, Kubota Y, Connolly CI, Hillegaart V, Graybiel AM (1999) Building neural representations of habits. Science 286:1745-1749.

Kreitzer AC, Malenka RC (2005) Dopamine modulation of state-dependent endocannabinoid release and long-term depression in the striatum. J Neurosci 25:10537-10545.

Lewis D, Teyler TJ (1986) Anti-S-100 serum blocks long-term potentiation in the hippocampal slice. Brain Res 383:159-164.

Li C, Sasaki Y, Takei K, Yamamoto H, Shouji M, Sugiyama Y, Kawakami T, Nakamura F, Yagi T, Ohshima T, Goshima Y (2004) Correlation between semaphorin $3 \mathrm{~A}$-induced facilitation of axonal transport and local activation of a translation initiation factor eukaryotic translation initiation factor 4E. J Neurosci 24:6161-6170.

Lovinger DM, Tyler EC, Merritt A (1993) Short- and long-term synaptic depression in rat neostriatum. J Neurophysiol 70:1937-1949.

Martin KC (2004) Local protein synthesis during axon guidance and synaptic plasticity. Curr Opin Neurobiol 14:305-310. 
Martin KC, Casadio A, Zhu H, Yaping E, Rose JC, Chen M, Bailey CH, Kandel ER (1997) Synapse-specific, long-term facilitation of Aplysia sensory to motor synapses: a function for local protein synthesis in memory storage. Cell 91:927-938.

Martin KC, Barad M, Kandel ER (2000) Local protein synthesis and its role in synapse-specific plasticity. Curr Opin Neurobiol 10:587-592.

Nauta WJH (1989) Reciprocal links of the corpus striatum with the cerebral cortex and limbic system: a common substrate for movement and thought? In: Neurology and psychiatry: a meeting of minds (Mueller, ed), pp 43-63. Basel: Karger.

Nishiyama H, Knopfel T, Endo S, Itohara S (2002) Glial protein S100B modulates long-term neuronal synaptic plasticity. Proc Natl Acad Sci USA 99:4037-4042.

Nosyreva ED, Huber KM (2005) Developmental switch in synaptic mechanisms of hippocampal metabotropic glutamate receptor-dependent longterm depression. J Neurosci 25:2992-3001.

Piper M, Holt C (2004) RNA translation in axons. Annu Rev Cell Dev Biol 20:505-523.

Ronesi J, Gerdeman GL, Lovinger DM (2004) Disruption of endocannabinoid release and striatal long-term depression by postsynaptic blockade of endocannabinoid membrane transport. J Neurosci 24:1673-1679.

Sherff CM, Carew TJ (1999) Coincident induction of long-term facilitation in Aplysia: cooperativity between cell bodies and remote synapses. Science 285:1911-1914.

Si K, Giustetto M, Etkin A, Hsu R, Janisiewicz AM, Miniaci MC, Kim JH, Zhu
H, Kandel ER (2003) A neuronal isoform of CPEB regulates local protein synthesis and stabilizes synapse-specific long-term facilitation in Aplysia. Cell 115:893-904.

Tsokas P, Grace EA, Chan P, Ma T, Sealfon SC, Iyengar R, Landau EM, Blitzer $\mathrm{RD}$ (2005) Local protein synthesis mediates a rapid increase in dendritic elongation factor $1 \mathrm{~A}$ after induction of late long-term potentiation. J Neurosci 25:5833-5843.

Wang Z, Kai L, Day M, Ronesi J, Yin HH, Ding J, Tkatch T, Lovinger DM, Surmeier DJ (2006) Dopaminergic control of corticostriatal long-term synaptic depression in medium spiny neurons is mediated by cholinergic interneurons. Neuron 50:443-452.

Willis D, Li KW, Zheng JQ, Chang JH, Smit A, Kelly T, Merianda TT, Sylvester J, van Minnen J, Twiss JL (2005) Differential transport and local translation of cytoskeletal, injury-response, and neurodegeneration protein mRNAs in axons. J Neurosci 25:778-791.

Yin HH, Knowlton BJ, Balleine BW (2004) Lesions of dorsolateral striatum preserve outcome expectancy but disrupt habit formation in instrumental learning. Eur J Neurosci 19:181-189.

Yin HH, Knowlton BJ, Balleine BW (2006) Inactivation of dorsolateral striatum enhances sensitivity to changes in the action-outcome contingency in instrumental conditioning. Behav Brain Res 166:189-196.

Zheng JQ, Kelly TK, Chang B, Ryazantsev S, Rajasekaran AK, Martin KC, Twiss JL (2001) A functional role for intra-axonal protein synthesis during axonal regeneration from adult sensory neurons. J Neurosci 21:92919303. 